\title{
The Micro-Elimination Approach to Eliminating Hepatitis C: Strategic and Operational Considerations
}

\author{
Jeffrey V. Lazarus, PhD, MIH, MA ${ }^{1}$ Kelly Safreed-Harmon, MSc $^{1}$ Mark R. Thursz, MD, FRCP2 \\ John F. Dillon, MB, BS, MD, FRCP ${ }^{3}$ Manal H. El-Sayed, MD ${ }^{4}$ Ahmed M. Elsharkawy, BM (Hons), \\ $\mathrm{PhD}, \mathrm{FRCP}^{5}$ Angelos Hatzakis, MD, PhD, $\mathrm{MSc}^{6}$ Michel Jadoul, $\mathrm{MD}^{7}$ Tullio Prestileo, $\mathrm{MD}^{8}$ \\ Homie Razavi, PhD ${ }^{9}$ Jürgen K. Rockstroh, MD ${ }^{10}$ Stefan Z. Wiktor, MD ${ }^{11}$ Massimo Colombo, MD ${ }^{12}$
}

${ }^{1}$ Barcelona Institute for Global Health (ISGlobal), Hospital Clínic, University of Barcelona, Barcelona, Spain

${ }^{2}$ Department of Surgery and Cancer, Imperial College, London, United Kingdom

${ }^{3}$ Division of Molecular and Clinical Medicine, School of Medicine, University of Dundee, Dundee, United Kingdom

${ }^{4}$ Department of Pediatrics, Ain Shams University, Cairo, Egypt

${ }^{5}$ University Hospitals Birmingham, Mindelsohn Way, Birmingham, United Kingdom

${ }^{6}$ Department of Hygiene, Epidemiology and Medical Statistics, National and Kapodistrian University of Athens Medical School, Athens, Greece

7 Department of Nephrology, Cliniques universitaires Saint-Luc,

Université catholique de Louvain, Brussels, Belgium

8 Infection Diseases Unit and Centre for Migration and Health, ARNAS, Civico-Benfratelli Hospital, Palermo, Italy

${ }^{9}$ Center for Disease Analysis Foundation, Lafayette, Colorado

10 Department of Medicine I, University of Bonn, Bonn, Germany

${ }^{11}$ Department of Global Health, University of Washington Schools of Medicine and Public Health, Seattle, Washington

12 Department of Medicine, Clinical and Research Center, Humanitas Hospital, Rozzano, Italy
Address for correspondence Jeffrey V. Lazarus, PhD, MIH, MA, Barcelona Institute for Global Health (ISGlobal), Hospital Clínic, University of Barcelona, Calle Roselló 132, 4th floor, ES-08036 Barcelona, Spain (e-mail: Jeffrey.Lazarus@isglobal.org).

Semin Liver Dis 2018;38:181-192.

\begin{abstract}
Keywords

- health policy

- hepatitis C

- micro-elimination

- health systems

- models of care

The introduction of efficacious new hepatitis C virus (HCV) treatments galvanized the World Health Organization to define ambitious targets for eliminating HCV as a public health threat by 2030 . Formidable obstacles to reaching this goal can best be overcome through a micro-elimination approach, which entails pursuing elimination goals in discrete populations through multi-stakeholder initiatives that tailor interventions to the needs of these populations. Micro-elimination is less daunting, less complex, and less costly than full-scale, country-level initiatives to eliminate $\mathrm{HCV}$, and it can build momentum by producing small victories that inspire more ambitious efforts. The micro-elimination approach encourages stakeholders who are most knowledgeable about specific populations to engage with each other and also promotes the uptake of new models of care. Examples of micro-elimination target populations include medical patients, people who inject drugs, migrants, and prisoners, although candidate populations can be expected to vary greatly in different countries and subnational areas.
\end{abstract}

The introduction of direct-acting antivirals (DAAs) for the treatment of hepatitis C virus (HCV) infection in 2013 is one of the greatest advances of the current biomedical era. Treatment with DAAs achieves sustained virological response (SVR) rates of $\geq$
$95 \%$ after 8 to 12 weeks of treatment for one of the leading causes of chronic liver disease and liver-related deaths worldwide. ${ }^{1-3}$ The efficacy of the new DAA treatment regimens galvanized the World Health Organization (WHO) to adopt its first-ever Global published online

July 9,2018
Copyright (c) 2018 by Thieme Medical Publishers, Inc., 333 Seventh Avenue, New York, NY 10001, USA. Tel: +1(212) 584-4662.
DOI https://doi.org/ 10.1055/s-0038-1666841. ISSN 0272-8087. 
Health Sector Strategy on Viral Hepatitis in 2016. The strategy defines ambitious time-bound targets for eliminating HCV as a public health threat by 2030. One key target for countries worldwide is to reduce new HCV cases by $80 \%$, and another key target is to reduce HCV-related deaths by $65 \%$ by $2030 .{ }^{4}$

Scaling up DAA treatment is essential for achieving the HCV targets, but this constitutes an enormous public health challenge. A major obstacle is underdiagnosis: only $20 \%$ of people with HCV worldwide have been diagnosed. ${ }^{2}$ While approximately 71 million people were thought to be infected with HCV in 2015, only 1.76 million people received HCV treatment in $2016 .^{5}$ Three-quarters of people with HCV live in low- and middle-income countries (LMICs), ${ }^{5}$ many of which lack the resources to stage major HCV testing and treatment campaigns. In January 2018, the Polaris Observatory reported that only 12 countries were on track to meet the 2030 WHO HCV elimination targets: Australia, Egypt, France, Georgia, Iceland, Italy, Japan, Mongolia, the Netherlands, Spain, Switzerland, and the United Kingdom. ${ }^{6}$

\section{What Is the Micro-Elimination Approach to Eliminating HCV?}

In 2017, the European Association for the Study of the Liver's International Liver Foundation suggested that stakeholders can best grapple with the complexity of the HCV elimination challenge by setting micro-elimination goals: "break[ing] down national elimination goals into smaller goals for individual population segments, for which treatment and prevention interventions can be delivered more quickly and efficiently using targeted methods."7 The following review builds on this concept by distinguishing a micro-elimination approach from efforts to merely reduce HCV prevalence, incidence, and mortality in specific populations. Generally speaking, micro-elimination approaches should meet the following criteria, although these criteria may need to be adapted to different epidemiological situations and geographic settings:

- There is a plan for how to tailor health resources and services to overcome known barriers and achieve high levels of HCV diagnosis and treatment in one or more clearly definable populations of interest within a specified timeframe.
- The plan sets forth achievable annual targets based on mathematical modeling, when relevant, to determine the levels of diagnosis and treatment required to progress to the plan's ultimate elimination targets.

- The plan is developed and implemented through a multistakeholder process, with essential participants including government officials, health service providers, and civil society representatives.

- Progress and outcomes are monitored and publicly reported using indicators selected at the outset of the process.

There can be a great deal of variation in the geographic scope of micro-elimination efforts. In some cases, it might be logical to pursue micro-elimination in a specific population nationally, whereas, in other cases, there are reasons to work on a smaller scale, such as regionally or at the city level. An initiative employing a micro-elimination approach might focus on only one population, or it might focus on all of the populations affected by HCV within a designated geographic area. In cases in which comprehensive national HCV elimination efforts are proposed or underway, such as in Iceland (Box 1), it may be the case that these efforts encompass multiple micro-elimination approaches. For the sake of conceptual clarity, however, we propose that efforts to eliminate HCV in all populations at the national level not be considered micro-elimination, even when the country has a very small population.

Activities targeting some of the smallest subpopulations of HCV-infected people, such as an initiative to cure HCV in all patients attending a single health clinic, would make welcome contributions to HCV elimination but might not actually embody the micro-elimination approach if the task at hand does not require a multi-stakeholder planning and implementation process. On the other hand, an effort to eliminate HCV in a population of the same size at a single prison would constitute micro-elimination if stakeholders engage in this undertaking in a way that embodies the aforementioned criteria. The microelimination approach particularly emphasizes choosing the interventions that are most relevant to the population of interest, tailoring these interventions in accordance with evidence about the population's needs, and tracking how the interventions contribute to progress toward publicly agreed-

\section{Box 1 What about macro-elimination?}

While the micro-elimination approach may be appealing to countries that are not yet prepared to fully implement national HCV elimination plans, it also speaks to the needs of countries pursuing full-scale elimination in that it emphasizes the importance of providing tailored services to reach specific populations whose engagement will be essential for success. Although the launch of Iceland's HCV elimination program predates the introduction of the micro-elimination concept, it provides an instructive example of how the micro-elimination approach can enhance national initiatives. Iceland, a country of 340,000 people, all covered by national health insurance, had an estimated viraemic HCV population of 1,100 in 2014, with most cases resulting from unsafe injecting drug use. ${ }^{80}$ In 2015, Gilead Sciences and Icelandic officials came to an agreement that Gilead would provide DAAs to all $\mathrm{HCV}$ patients for 36 months. The program was launched in January $2016 .{ }^{80}$ Its overall strategy has been to treat all HCV patients in Iceland within a short timeframe while providing harm-reduction measures such as needle-and-syringe services and opioid substitution therapy to achieve a rapid decline in new infections. HCV testing and treatment are available to all people regardless of whether they agree to participate in the research arm, which will monitor long-term outcomes. Active outreach and travel assistance are provided to encourage people to take advantage of the program. ${ }^{80}$ It is expected that this aggressive, multipronged initiative will result in Iceland eliminating HCV well ahead of the WHO timeline as well as providing evidence that will aid other countries pursuing elimination goals. ${ }^{80}$ In the first 15 months of the program, 554 people with HCV were evaluated, of whom 94\% initiated treatment. Viremic HCV prevalence among PWID dropped from 43\% at baseline to 12\% in 2017, a $72 \%$ reduction. 109 
upon elimination goals. Preferably, those goals would align with the global goals set by $\mathrm{WHO}{ }^{4}$

While pursuing a micro-elimination strategy requires grouping people with HCV infection into different populations, some individuals are, in reality, members of more than one population. Hence, an HCV-infected migrant who injects drugs, for example, might be engaged in care through more than one micro-elimination pathway. At the same time, multiple pathways might be required to reach different subgroups within the same population. A micro-elimination program targeting people who inject drugs (PWID), for example, might need to use different types of service delivery models for PWID who are receiving opioid substitution therapy and those who are not, or for PWID who are incarcerated versus those in the community.

HCV-infected children fall into many of the populations described in this article as potential micro-elimination targets, including aboriginal and indigenous communities, migrants, and PWID. It is important to consider the ways in which children and adults differ from each other in regard to their HCV prevention and treatment needs (Box 2). Women of childbearing age constitute another group that warrants special consideration across micro-elimination initiatives in different populations. The estimated global number of women of childbearing age (aged 15-44 years) who have HCV viremia is 13 million, ${ }^{8}$ with injecting drug use thought to account for increasing numbers of infected women and children in some settings in recent years. ${ }^{9,10}$ Children and women of childbearing age, generally speaking, may not be practical microelimination targets because both populations are so large and diverse that tailored interventions would still be needed for many different subpopulations. It is advisable for micro-elimination strategies targeting almost all populations to take into account whether the needs of children and women of childbearing age within those populations are being addressed. In some settings, HCV epidemic dynamics might argue in favor of developing micro-elimination initiatives specifically targeting populations such as children receiving inpatient hospital care or women of childbearing age in prisons, to name two of many possible examples.

The micro-elimination approach is not meant to override medical and ethical standards widely endorsed by the global community of HCV stakeholders; it is instead offered to aid strategic decision-making in situations where the most appropriate use of resources is not already clear. Furthermore, as everyone holds the same human rights to health services, it is essential to provide a strong rationale for why some populations are being chosen over others for microelimination programs, along with a commitment to address the HCV-related needs of those other populations in conjunction with pursuing micro-elimination. International human rights standards, in fact, call for governments to set targets for when resources initially allocated to priority populations will be made available to everyone in need-a concept known as progressive realization. ${ }^{11}$ In other words, a health system cannot use a micro-elimination initiative targeting patients undergoing hemodialysis, for example, as an excuse to turn its back on HCV-infected PWID or migrants. National and subnational HCV elimination plans must take into account all HCV-affected populations and must set goals and targets accordingly; the micro-elimination approach merely constitutes a method of focusing and organizing on-the-ground activities to take tangible steps toward the larger goal of eliminating $\mathrm{HCV}$ in the entire population. $^{12}$

An essential component of HCV elimination is reducing transmission by infected people who have not yet been treated or not responded to treatment. Prevention thus needs to remain a prominent element of national and subnational responses to $\mathrm{HCV}$. There are large gaps in $\mathrm{HCV}$ prevention services in many LMICs with high HCV prevalence. As a global micro-elimination agenda emerges, this agenda must not be permitted to draw attention and resources away from some of the most basic HCV prevention needs of LMICs. For example, there are unrealized opportunities to reduce nosocomial transmission of HCV in some LMICs. ${ }^{13}$ Furthermore, many LMICs have yet to acknowledge the importance of PWID populations in their countries. As such, there is a dearth of opioid substitution therapy services and needle-and-syringe programs. ${ }^{14}$ The global community of HCV stakeholders, including funders, should continue to make it a priority to foster health system policies and interventions addressing $\mathrm{HCV}$ prevention.

\section{Box 2 Children and HCV}

Estimates of prevalence of HCV in children and adolescents range from between 0.05 to $0.36 \%$ in high-income countries to between 1.8 to $5.8 \%$ in some heavily affected low-income countries, but it is likely that these data severely underestimate actual prevalence. ${ }^{110}$ There are notable differences in how HCV manifests in children and adults, including progression of liver damage, clearance rates, treatment options, and length of potential chronic infection. ${ }^{43,111}$ Most infection in children is due to vertical transmission, but injecting drug use is thought to be an increasingly common infection route among older children in some settings in the United States. ${ }^{9}$ Children with HCV generally experience less severe liver disease than their adult counterparts. Spontaneous clearance rates are slightly higher for children than adults, mostly among children infected through vertical transmission, who have a 25 to $40 \%$ chance of spontaneous viral clearance. ${ }^{43}$ Treatment options for children with HCV lag well behind those for adults. Only in 2017 were the first DAA treatments approved for adolescents (aged 12-17 years), and although studies on younger children are underway, currently the only treatments available for them are interferon-based, which tend to be less effective and more toxic. ${ }^{5,111}$ Because of the side effects of interferon-based treatments and the generally slow progression of liver disease in children, as well as the expectation of increasing availability of DAAs for children, treatment is not currently advised for children under the age of 12 years in most cases. ${ }^{5,111}$ 


\section{Why Take a Micro-Elimination Approach?}

The challenges associated with eliminating HCV encompass both logistic and political considerations: many health systems are not prepared to massively increase HCV prevention, testing, and treatment activities, whereas many stakeholders who influence the allocation of financial and human resources are not convinced of the need to prioritize HCV or are unable to come to an agreement on how HCV elimination targets should be pursued. The micro-elimination approach can present pathways for overcoming these issues. Micro-elimination is likely to strike stakeholders as less daunting, less complex, and less costly than full-scale country-level initiatives to comprehensively eliminate HCV. In the many countries that have not formally established the goal of HCV elimination, setting and achieving micro-elimination goals can serve as a step in this direction, with early successes inspiring more ambitious efforts.

From a public health standpoint, a key feature of HCV is that its diverse transmission routes have resulted in the spread of the disease among a wide range of populations. The micro-elimination approach encourages stakeholders who are the most knowledgeable about specific populations to engage with each other. Having the goal of eliminating HCV among all patients on hemodialysis nationally, for example, might foster collaboration among diverse stakeholders who can help drive progress, including different types of clinical specialists, various cadres of health care workers, public health officials, and patient groups. Furthermore, organizing around micro-elimination goals could create opportunities for cross-border collaboration, for example, hemophilia patient groups working at the regional or global level might be asked by their in-country counterparts to help lobby governments to adopt micro-elimination targets. A micro-elimination approach could also encourage the uptake of new models of care, such as the co-location of services or shifting of HCV testing and treatment sites to different hospital departments or outside of hospital settings. ${ }^{15-19}$

Micro-elimination approaches in populations at high risk of transmitting $\mathrm{HCV}$ can potentially contribute to "treatment as prevention." ${ }^{20}$ The concept of treatment as prevention is to successfully treat an $\mathrm{HCV}$-infected person who is at a risk of passing the virus on to others and eliminate the possibility of further transmission, thereby achieving "prevention." While there is not yet a real-world demonstration of the potency of treatment as prevention, modeling indicates that carrying out this strategy on a sufficiently large scale accelerates progression to population elimination, with especially notable gains seen when PWID are the focus in HCV epidemics driven by injecting drug use. ${ }^{21,22}$ In other words, if a large proportion of HCVinfected PWID in a specific geographic area undergo successful treatment and achieve SVR, this will result in a sharp drop in the number of HCV-infected people who have the potential to transmit the disease to others with whom they share injecting equipment. ${ }^{20}$ The aim of treatment as prevention is to successfully treat enough people to reach a threshold where new infections are greatly reduced. Because of the potential to prevent further infections, many of which would incur the high costs of treating end-stage liver disease, models suggest that high levels of treatment combined with other preventive measures may prove cost-effective, especially if indirect costs such as loss of earnings due to disability are considered. ${ }^{23,24}$

While a micro-elimination approach is not required to take advantage of treatment as prevention, it presents the opportunity to comprehensively engage in processes that make treatment as prevention more likely to be successful, for example, the involvement of a broad coalition of stakeholders and the careful tracking of changes in HCV incidence and prevalence.

\section{Which Populations Should Be Targeted for Micro-Elimination?}

Candidate populations for HCV micro-elimination approaches can be expected to vary greatly in accordance with the epidemiology and health context of different countries and subnational areas. In this review, we discuss key features of 10 candidate populations. Other populations also warrant attention, and researchers and technical experts are encouraged to publish information about all potential micro-elimination populations to move this aspect of HCV elimination forward. Given that affected populations are not the same across all countries, the following subsections are arranged alphabetically to avoid the implication that some populations should be uniformly prioritized above others.

\section{Aboriginal and Indigenous Communities}

Some aboriginal and indigenous communities are disproportionately affected by $\mathrm{HCV}$, including communities in Australia, ${ }^{25}$ Canada, and the United States. For example, the acute $\mathrm{HCV}$ infection rate for American Indian and Alaska Native (AI/AN) populations was approximately twofold higher than that of non-Hispanic whites in the United States in 2015, whereas the HCV-associated mortality rate was threefold higher than that of non-Hispanic whites. ${ }^{26}$ Studies have indicated that HCV prevalence may be three to eight times higher in some Aboriginal Canadian populations than in non-Aboriginal Canadian populations. ${ }^{27,28}$ While there are limited data from Latin America, a Colombian study found 5.7\% HCV antibody prevalence among Amerindians belonging to four ethnic groups. ${ }^{29}$ In contrast, overall HCV antibody prevalence in Columbia is estimated to be $1.1 \%{ }^{30}$

Isolation, rural location, poverty, and communication barriers, as well as cultural beliefs can all contribute to lack of testing and treatment uptake in aboriginal and indigenous populations. ${ }^{31,32}$ Studies in Australia and the United States have documented good outcomes for HCV testing and treatment programs targeting aboriginal and $\mathrm{AI} / \mathrm{AN}$ populations, ${ }^{33,34}$ and the success of one U.S. initiative led to the launch of the Cherokee Nation HCV elimination program in 2015. ${ }^{35}$ There appears to be little other research to guide the design of HCV elimination interventions for aboriginal and indigenous communities. 


\section{Birth Cohorts with High HCV Prevalence}

In many countries, a group of people born in a specific span of years have a higher prevalence of HCV infection than the general population. This group is known as a "birth cohort." This "cohort effect" occurs due to changing infection modes. In some countries, for instance, many HCV infections are attributable to unsafe medical procedures that were largely eliminated when the danger was recognized and better infection control measures were put into place. ${ }^{2}$ The span of cohorts affected varies across countries. ${ }^{36-38}$ While in the United States, people born between 1945 and 1965 are at a higher risk, ${ }^{26}$ the Mexican cohort is older ${ }^{37}$ and the Czech Republic cohort is younger. ${ }^{36}$ Meanwhile, Poland appears to have no correlation between age and HCV prevalence. ${ }^{39}$ The possible existence of an at-risk birth cohort thus needs to be investigated on a country-by-country basis. In countries where there are birth cohorts with high HCV prevalence, a key advantage of birth-cohort testing is that it removes potential stigma from testing, as everyone within the age group is tested regardless of behavior, removing the perception of blame. ${ }^{40}$ A review examining the cost-effectiveness of interventions, which included eight studies evaluating birth cohorts in four countries (all with known high-risk birth cohorts $\sim 50$ years of age and older), found that in all instances, birth-cohort testing was cost-effective when compared with either the status quo or even riskbased testing. ${ }^{40}$ Similar results were found in Switzerland where far fewer people needed to be screened in specific cohorts to find one new HCV infection as compared with the general population. ${ }^{38}$ Despite this, global stakeholders have been slow to add birth-cohort analysis to their recommendations, and the first-ever WHO Global Health Sector Strategy on Hepatitis 2016-2021 fails to make any mention of it. ${ }^{4}$ One-time HCV testing of patients in high-risk cohorts has been recommended for both the United States and European countries ${ }^{41}$ and may be found useful in countries with a clearly identifiable at-risk birth cohort. However, defining this cohort requires population-based seroprevalence data, and not many countries have conducted the large and expensive national surveys that are required to obtain these data.

\section{Children of HCV-Infected Mothers}

Mother-to-child transmission of HCV is the primary mode of infection for children. According to a 2014 systematic review, there is a $5.8 \%$ risk of mother-to-child HCV transmission among HIV-negative women, and a $10.8 \%$ risk among HIV-positive women. ${ }^{42}$ Although this represents a low transmission risk per individual case, mother-to-child transmission still may add considerably to the burden of HCV disease. Unfortunately, there are several barriers to both identification and treatment in children of HCV-infected mothers. Although RNA testing is accurate at as early as 2 months of age, antibody testing of infants less than 15 months of age is complicated by the presence of maternal antibodies. ${ }^{43,44} \mathrm{~A}$ prospective study in Tennessee found that more than half of the infants of HCV-infected mothers left pediatric care prior to the 18 -month appointment at which they would be tested for $\mathrm{HCV},{ }^{45}$ indicating that loss to follow-up is potentially a major challenge in this population. Furthermore, although DAAs have been approved in children aged 12 to 17 years, studies for younger children have not yet been completed. ${ }^{44}$ Because of these limitations, HCV-infected children are likely to remain infected for an extended time, making it all the more important that they receive regular liver function tests and HCV RNA quantification until they reach an age at which they are eligible for treatment with DAAs. ${ }^{44}$

Regarding the issue of how more HCV-infected children can be diagnosed, current WHO guidelines recommend against routinely testing pregnant women in the general population for $\mathrm{HCV}^{46}$ reflecting the lack of evidence of this approach being cost-effective. ${ }^{47}$ In the context of developing micro-elimination strategies targeting children in specific settings, it may be advisable to consider the possible role of universal screening of pregnant women in those settings. This is a rapidly evolving area of research, and new evidence may influence changes in guidelines and best practices.

\section{Hemodialysis Recipients}

The transmission of HCV to hemodialysis patients has declined over the years due to better screening of blood products, improved dialysis procedures, and less need for blood transfusion with the availability of erythropoiesisstimulating agents. Nonetheless, HCV prevalence remains far higher in people receiving hemodialysis than in the general population. ${ }^{48-50}$ In low-income countries, both transfusion of contaminated blood products and hand-borne nosocomial transmission continue to be major infection pathways, ${ }^{13}$ but for high-income countries, the latter is currently the key pathway. ${ }^{51}$ Interferon-based therapies are not well tolerated by hemodialysis patients, as reflected in treatment rates of 1 to $4 \%$ in high-income countries. ${ }^{51-53}$ DAAs, however, are proving to be well-tolerated and effective in this population. ${ }^{49,54,55}$ Because patients with chronic kidney disease and HCV infection may lose kidney function at an accelerated rate compared with HCV-negative patients, and because HCV can cause complications in post-kidneytransplant patients, it is often recommended that patients receive treatment prior to transplantation, ${ }^{53,56,57}$ unless an $\mathrm{HCV}$-infected graft is rapidly available and HCV treatment can be provided following transplantation. Acute HCV infection is frequently asymptomatic, and regular screening is advised from the start of maintenance hemodialysis. ${ }^{49,58}$ Spontaneous clearance is rare among hemodialysis patients, so treatment should be provided as soon as possible. ${ }^{51}$ Thorough training and strict adherence to infection control protocols by staff are necessary to prevent future infections. ${ }^{48,58}$ There also is a need for rigorous screening to ensure that no new recipients of hemodialysis have HCV since such cases would allow for the reintroduction of HCV in hemodialysis units where progress has been made toward HCV elimination. The widespread treatment of HCV in people receiving hemodialysis will likely achieve the "treatment as prevention" outcome of reducing the incidence of transmission in hemodialysis units when paired with appropriate prevention measures. ${ }^{59}$ 


\section{HIV|HCV-Coinfected People}

It is estimated that worldwide, at least 2.3 million people are coinfected with HIV/HCV. ${ }^{60}$ People come to be coinfected with HIV/HCV through various pathways, often related to ongoing risk factors; common modes of transmission include the use of unsterile injecting drug equipment and sexual transmission between men. Reinfection is a particular challenge in men who have sex with men (MSM), with a reinfection rate of $25 \%$ observed in a large Western European cohort after 2 years of follow-up. ${ }^{61}$ Regular HCV testing is therefore recommended. Since HIV therapy needs to be given lifelong, and follow-up visits are regularly scheduled, such patients are readily available for HCV testing and, if necessary, treatment. Two studies from the Netherlands and Switzerland have shown that high rates of DAA treatment uptake by their HIV/HCV-coinfected cohorts reduced new acute HCV infections in MSM by around $50 \%,{ }^{62,63}$ suggesting a treatment-asprevention effect that would make elimination far more feasible. Coinfection with HIV does not impact the effectiveness of HCV treatment: equally high SVR rates can be found in $\mathrm{HIV} / \mathrm{HCV}$-coinfected patients as in $\mathrm{HCV}$-monoinfected patients. ${ }^{64,65}$

\section{Migrants from High-Prevalence Countries}

Due to risk factors such as HCV prevalence in their country of origin, countries visited during their journey as migrants, and the conditions they experienced during migration, immigrants and refugees (collectively referred to in this article as migrants) are at an elevated risk of being infected with HCV as well as having other health problems. Migrants often remain unidentified and thus untreated. According to a 2015 review, anti-HCV prevalence among migrants is $1.9 \%$ overall, with higher rates associated with region of origin, particularly Eastern Europe, Asia, and Sub-Saharan Africa. ${ }^{66}$ Factors that often limit HCV testing in migrant populations include lack of knowledge about where and how to get tested, concern for how a positive result might affect the host country's acceptance, lack of primary health care, and providers' possible reluctance to test for chronic conditions in patients they may never see again. ${ }^{67}$ Furthermore, because they may not belong to populations that the host country considers to be at a high risk, current screening practices may allow migrants to fall through the cracks and remain untested. ${ }^{66,68}$ Although migration status in and of itself is not an indicator for $\mathrm{HCV}$, region of origin is; migrants from countries with a high and moderate prevalence of $\mathrm{HCV}$ are at a greater risk of infection. ${ }^{66}$ There have been some efforts to reach this marginalized population. An HCV screening program started in southern Italy in 2012 not only tested undocumented immigrants and low-income refugees but also offered treatment and linkage to care, ${ }^{69}$ with results that clearly demonstrated the feasibility of retaining migrant patients throughout the testing and treatment process. ${ }^{67}$ Another Italian study, based in Palermo, retained $87 \%$ of patients and achieved SVR in $100 \%$ of the treated patients. ${ }^{70}$ A successful micro-elimination strategy targeting migrants from high-prevalence countries must include provision for screening and linkage to care, as well as cultural mediators for translation and explanation of the importance of screening and treatment. ${ }^{69}$

\section{People Who Inject Drugs}

Globally, PWID account for $8 \%$ of all chronic HCV infections and $23 \%$ of new infections, ${ }^{5}$ making them a large and growing segment of the HCV burden. They are a particularly important population to treat, both because of their high prevalence and because of the dynamic spread of infection among the larger population. ${ }^{71}$ This situation makes it likely that "treatment as prevention" will need to play a key role in eliminating HCV in PWID. Unfortunately, because injecting drug use is often stigmatized and even illegal, PWID are often reluctant to seek out or accept medical help. Health systems frequently impose barriers relating to a lack of housing or a permanent address, are inflexible with locations and appointment times, and are physically distant from the person, with travel costs being prohibitive. Some countries also do not provide antiviral treatment to current drug users. There is, however, extensive evidence that PWID can be effectively targeted and treated. ${ }^{20,72-74}$ For example, studies in Scotland and Iceland found that it was possible to cure active drug users of $\mathrm{HCV} ;{ }^{75,76}$ nurse-led models of care have proven efficacious in improving access to care and achieving successful treatment outcomes; ${ }^{77,78}$ and a communitybased public health facility in Sydney, Australia, found that PWID can be successfully treated for HCV using an integrated primary health-care model. ${ }^{79}$ The Australian initiative also demonstrated the feasibility of scaling up DAA therapy in high-risk PWID populations, with potential individual and population-level public health benefits.

People who inject drugs need specific care pathways for HCV diagnosis and treatment, and these pathways should be based around facilities and services that they are already accessing. Because many PWID already use opioid substitution therapy as well as needle-and-syringe programs, the facilities and locations where these interventions and treatments take place are ideal for new HCV diagnosis and treatment initiatives. There are also models for engaging PWID who do not seek out these services. In Iceland, for example, the national HCV elimination program has targeted homeless shelters as part of its extensive outreach measures. ${ }^{80} \mathrm{HCV}$ treatment should be provided to PWID as part of the comprehensive package of interventions recommended by WHO, the United Nations Programme on HIV/ AIDS, and the United Nations Office on Drugs and Crime for HIV prevention, treatment, and care for injecting drug users. This landmark guidance document calls for viral hepatitis prevention, vaccination, diagnosis, and treatment along with key harm-reduction services such as opioid substitution therapy and needle-and-syringe programs. ${ }^{81}$

Health systems with a wide range of epidemiological scenarios can benefit from targeting PWID for micro-elimination. It is believed that with expanded screening for HCV, especially among PWID, Iceland could reach the WHO targets by 2020 , becoming one of the first countries to achieve HCV elimination. ${ }^{82}$ The government of Iceland committed to a comprehensive elimination program despite the fact that the 
country's estimated HCV-infected population in 2014 was only $1,100 .^{80}$ Georgia, a country with a much higher HCV burden, has developed an elimination pilot program that includes intensified HCV detection efforts and increased harm-reduction services for PWID. ${ }^{83,84}$ In the United Kingdom, the Tayside region of Scotland is being used as a test bed of regional micro-elimination, using an integrated combination of pathways to target all groups infected with HCV, especially focusing on treatment of PWID in needle-andsyringe programs, to prove the concept of "treatment as prevention." The complementary service pathways include conventional nurse-led outreach programs, pharmacist-led treatment of patients on opioid substitution therapy in community pharmacies, treatment in prisons, and treatment by embedded hepatitis specialist nurses in addiction treatment centers. It is anticipated that all of these services will deliver the volume of treatment modeled to reduce prevalence to below $10 \%$ and incidence to below $1 \%$ over 3 years, thereby achieving elimination. ${ }^{85}$

\section{People with Hemophilia and Other Inherited Blood Disorders}

Prior to 1990, transfusion of blood and blood products was the primary vector for transmission of HCV infection in people with hemophilia and other hereditary blood disorders, such as von Willebrand's disease and thalassemia. ${ }^{86}$ The burden of HCV disease remains high in this population, even in high-income countries where there have been almost no new cases of HCV in patients with hemophilia in recent years. People with hemophilia have much higher mortality due to chronic HCV than the general population. ${ }^{86}$ In the past, these patients often declined interferon-based HCV treatment due to side effects, but DAAs are much better tolerated and are highly effective in this population. A Japanese study investigated the safety and efficacy of DAAs among 27 individuals with hemophilia and HCV/HIV coinfection. All study patients achieved SVR after receiving interferon-free DAA therapy. ${ }^{87}$ In the United States, Walsh et al found similar results in a study that enrolled individuals with chronic HCV and inherited blood disorders (hemophilia and von Willebrand's disease). ${ }^{88}$ Patients with thalassemia have also responded well to DAA treatment, with high SVR rates and few side effects, even those who had not responded to previous interferon treatment and were considered difficult to treat. ${ }^{89,90}$ These studies suggest that individuals with inherited blood disorders may safely and successfully be treated for HCV with DAA therapy. ${ }^{88}$ Ireland's elimination of HCV in patients with hemophilia ${ }^{91}$ (Box 3) and Slovenia's elimination of $\mathrm{HCV}$ in patients with all congenital bleeding disorders $^{92}$ suggest that the lack of new infections and effectiveness of DAA treatment make micro-elimination in these groups of patients highly achievable.

\section{Prisoners}

Prisoners in most countries have a higher prevalence of HCV than the general population, but their access to treatment is very limited. ${ }^{2,93}$ Although this high prevalence is in part due to conditions and experience prior to incarceration, with drug use, tattooing, and sexual activity being high-risk factors, stresses within prisons such as overcrowding and violence can cause inmates to begin or continue unsafe activities, resulting in a 30\% estimated rate of new infections annually. ${ }^{93}$ Barriers to treatment include lack of testing, social stigma, and lack of availability of treatment options. HCV interventions, including treatment, can be delivered safely and effectively in prison settings and should be an essential component of any national elimination strategy. ${ }^{94,95}$ Treatment within prisons has been shown to be cost-effective in Scotland, even at DAA costs that are now historical. ${ }^{96}$

A rapid DAA scale-up program initiated at a correctional facility in Cairns, Australia, as part of a larger elimination strategy resulted in a fall in the prevalence of HCV viremia within the prison from approximately $12 \%$ to less than $1 \%$ over a 22-month period, thereby effectively achieving HCV micro-elimination in this institution. ${ }^{97}$ Six reinfections were seen in the population studied, which underscores the risk of incident cases of HCV continuing to occur unless strong efforts are made to improve harm-reduction services in

Box 3 Eliminating HCV in people with hemophilia: the Irish experience

Ireland implemented a strategy with elements of the micro-elimination approach in its elimination of HCV in people with
hemophilia. In 1999 to 2001 , Ireland held a tribunal inquiring into HCV and HIV in hemophiliacs and others who were
infected through blood and blood products provided by the State. Its findings led the tribunal to call for the creation of a
coordinating committee focusing on the care and treatment of patients with hemophilia, as well as for better
communication among doctors caring for patients with hemophilia. ${ }^{112}$ In response, stakeholders formed the National
Haemophilia Council, an advisory board comprising a wide range of public health officials, advocacy groups, and medical
professionals. When DAAs became available, the National Haemophilia Council and other groups advocated strongly for
them to be offered to patients with hemophilia. The Department of Health consequently assured the Council that all
State-infected patients would receive treatment beginning in mid-2015. This goal was met, and at the end of 2016 , it was
announced that hepatitis C had been eliminated among patients with hemophilia in Ireland. ${ }^{113}$
Although Ireland was successful, a true micro-elimination approach would include more specific quantitative goals and
more detailed reporting of plans, progress, and outcomes to make the process fully transparent. A notable lesson to take
away from the Irish experience is that a history of effective multi-stakeholder collaboration in response to the health needs
of some HCV-affected populations may provide a good foundation for a micro-elimination initiative. Ireland now has a
hepatitis elimination plan for the country, with 2026 as the target year. ${ }^{114}$ The program is supported by a clinical advisory
group made up of health-care professionals involved in the delivery of care to patients with HCV across several disciplines.


prisons. ${ }^{98,99}$ Nurse-led and specialist-supported models of care in Australian correctional facilities have been demonstrably effective in increasing treatment uptake among inmates with chronic $\mathrm{HCV}$, with treatment responses in excess of $95 \%$ in some facilities. ${ }^{100,101}$ A study in Spain reported a $>99 \%$ adherence rate and a prevalence drop from 9.9 to $0.5 \%$ during the year it was implemented. All treated inmates achieved SVR after 8 or 12 weeks of treatment. ${ }^{102}$ Notably, this study also created a sustainable model for continuance: even after its completion, all new prisoners are offered treatment. ${ }^{103}$ Rapid HCV testing and DAA treatment can also feasibly be delivered in transient jail populations, where inmates are often detained for fairly short or unpredictable periods of time, as observed by two studies conducted in the United States. ${ }^{95,104}$ In many countries, however, it is common for remand prisoners to be incarcerated for 1 week or less. Initiatives that target remand prisoners for HCV testing and treatment thus need to have a strong linkage-to-care component with effective mechanisms for transferring care from the prison setting to the community setting upon release.

\section{Transplant Recipients}

$\mathrm{HCV}$ infection increases mortality and graft loss in transplant recipients, ${ }^{53,55,105}$ making them an important target group for a micro-elimination approach. In the past, HCV treatment after transplant was fraught with poor tolerance and was often unsuccessful. New DAA treatments have proven to be both safe and effective, and all transplant recipients who are viremic for HCV should be offered treatment before or after transplant. ${ }^{58}$ Therefore, the question in transplant recipients is less a matter of whether to treat HCV but when to do so. The majority of transplant recipients should be treated prior to surgery, but in a small subset of patients whose liver disease is so advanced that pre-transplant DAA therapy is either unsafe or unlikely to be effective, treatment should be delayed until after surgery. There are increasing calls to consider using HCV-positive organs in HCV-negative recipients, ${ }^{106,107}$ but this practice should be implemented only in the context of timely access to DAA therapy.

\section{Conclusion}

The micro-elimination approach discussed in this article has the potential to catalyze progress against HCV in a diverse range of epidemiological settings. Stakeholders pursuing HCV elimination targets in countries worldwide should work together to further develop a micro-elimination agenda that will enhance their efforts. Such an agenda should call for rigorous research including social science research to document the outcomes of micro-elimination initiatives. The monitoring of micro-elimination outcomes should incorporate key indicators of progress toward the WHO HCV elimination targets. WHO's proposed viral hepatitis monitoring framework contains several indicators that are relevant for HCV micro-elimination initiatives, including prevalence of HCV infection, people living with HCV diagnosis, treatment initiation, cure, and deaths from hepatocellular carcinoma, cirrhosis, and liver diseases attributable to $\mathrm{HCV}^{108}$ It is advisable to draw from the WHO indicators as much as possible in developing monitoring frameworks for microelimination initiatives, as this will facilitate comparisons of outcomes and will allow for the aggregation of data across different settings.

Research and stakeholder consultation are needed to develop decision-making tools for health systems that are exploring how to make the most strategic use of the microelimination approach. Several candidate micro-elimination populations are relatively easy to reach because they are already patients in care, for example, for kidney disease, HIV, or opioid substitution therapy. However, these populations do not necessarily include the largest numbers of HCV-infected people or the ones at the greatest risk of transmitting the disease to others. A much greater expenditure of resources may be required to reach $\mathrm{HCV}$-infected people who are not already in care, but the return on the investment could potentially be greater strides toward elimination. Navigating decisions about which populations to prioritize will require a much better evidence base than what is currently available. The publication of real-world operational research findings will greatly advance the micro-elimination agenda in the coming years and will aid stakeholders in combining different micro-elimination models to achieve full-scale elimination and reach the 2030 HCV elimination targets.

\section{Acknowledgments}

The authors thank Eve Peters-Campbell for providing research and editorial support.

\section{References}

1 Polaris Observatory HCV Collaborators. Global prevalence and genotype distribution of hepatitis C virus infection in 2015: a modelling study. Lancet Gastroenterol Hepatol 2017;2(03):161-176

2 World Health Organization. Global Hepatitis Report, 2017. Geneva: World Health Organization. http://apps.who.int/iris/bitstream/ 10665/255016/1/9789241565455-eng.pdf. Accessed April 26, 2018

3 GBD 2013 Mortality and Causes of Death Collaborators. Global, regional, and national age-sex specific all-cause and cause-specific mortality for 240 causes of death, 1990-2013: a systematic analysis for the Global Burden of Disease Study 2013. Lancet 2015;385(9963):117-171

4 World Health Organization. Global Health Sector Strategy on Viral Hepatitis, 2016-2021: Towards Ending Viral Hepatitis. Geneva: World Health Organization. http://apps.who.int/iris/bitstream/ 10665/246177/1/WHO-HIV-2016.06-eng.pdf. Accessed April 26, 2018

5 World Health Organization. Progress Report on Access to Hepatitis C Treatment: Focus on Overcoming Barriers in Low- and Middle-Income Countries. Geneva: World Health Organization. 2018. http://apps.who.int/iris/handle/10665/260445. Accessed April 26, 2018

6 The Polaris Observatory. News. Available at: http://cdafound. org/news/. Accessed June 27, 2018

7 Lazarus JV, Wiktor S, Colombo M, Thursz M; EASL International Liver Foundation. Micro-elimination - a path to global elimination of hepatitis C. J Hepatol 2017;67(04):665-666

8 The Polaris Observatory. Untitled. Available at: http://cdafound. org/polaris/. Accessed June 27, 2018 
9 Centers for Disease Control and Prevention(CDC). Hepatitis C virus infection among adolescents and young adults:Massachusetts, 2002-2009. MMWR Morb Mortal Wkly Rep 2011;60(17):537-541

10 Patrick SW, Bauer AM, Warren MD, Jones TF, Wester C. Hepatitis $C$ virus infection among women giving birth - Tennessee and United States, 2009-2014. MMWR Morb Mortal Wkly Rep 2017; 66(18):470-473

11 Office of the United Nations High Commissioner for Human Rights. Frequently Asked Questions on Economic, Social and Cultural Rights: Fact Sheet No. 33. 2008. Available at: http:// www.ohchr.org/Documents/Publications/FactSheet33en.pdf

12 Lazarus JV, Pericàs JM, Hetherington KL. Micro-elimination - a key component of global hepatitis C elimination. In: Hatzakis A, ed. Epidemiology, Prevention, Management and Elimination of Hepatitis C - Volume III Elimination of HCV. Springer; 2018 ( in press )

13 Thursz M, Fontanet A. HCV transmission in industrialized countries and resource-constrained areas. Nat Rev Gastroenterol Hepatol 2014;11(01):28-35

14 Howard A, Stone K. The Global State of Harm Reduction 2016. London: Harm Reduction International; 2016. https://www.hri.global/files/2016/11/14/GSHR2016_14nov.pdf. Accessed 01 May 2018

15 Bruggmann P, Litwin AH. Models of care for the management of hepatitis $C$ virus among people who inject drugs: one size does not fit all. Clin Infect Dis 2013;57(Suppl 2):S56-S61

16 Tait JM, Wang H, Stephens BP, et al. Multidisciplinary managed care networks-Life-saving interventions for hepatitis $\mathrm{C}$ patients. J Viral Hepat 2017;24(03):207-215

17 Radley A, Melville K, Tait J, Stephens B, Evans JMM, Dillon JF. A quasi-experimental evaluation of dried blood spot testing through community pharmacies in the Tayside region of Scotland. Frontline Gastroenterol 2017;8(03):221-228

18 Radley A, Tait J, Dillon JF. DOT-C: a cluster randomised feasibility trial evaluating directly observed anti-HCV therapy in a population receiving opioid substitute therapy from community pharmacy. Int J Drug Policy 2017;47:126-136

19 Mathur P, Comstock E, McSweegan E, Mercer N, Kumar NS, Kottilil S. A pilot study to expand treatment of chronic hepatitis C in resource-limited settings. Antiviral Res 2017;146:184-190

20 Leask JD, Dillon JF. Review article: treatment as prevention targeting people who inject drugs as a pathway towards hepatitis C eradication. Aliment Pharmacol Ther 2016;44(02):145-156

21 Fraser H, Martin NK, Brummer-Korvenkontio H, et al. Model projections on the impact of $\mathrm{HCV}$ treatment in the prevention of HCV transmission among people who inject drugs in Europe. J Hepatol 2018;68(03):402-411

22 Gountas I, Sypsa V, Anagnostou O, et al. Treatment and primary prevention in people who inject drugs for chronic hepatitis $C$ infection: is elimination possible in a high-prevalence setting? Addiction 2017;112(07):1290-1299

23 Ayoub $\mathrm{HH}$, Abu-Raddad LJ. Impact of treatment on hepatitis C virus transmission and incidence in Egypt: a case for treatment as prevention. J Viral Hepat 2017;24(06):486-495

24 Hickman M, De Angelis D, Vickerman P, Hutchinson S, Martin NK. Hepatitis $C$ virus treatment as prevention in people who inject drugs: testing the evidence. Curr Opin Infect Dis 2015;28(06):576-582

25 Kirby Institute. Bloodborne Viral and Sexually Transmissible Infections in Aboriginal and Torres Strait Islander People: Annual Surveillance Report 2017. Sydney: Kirby Institute, UNSW Sydney; 2017. https://kirby.unsw.edu.au/sites/default/files/kirby/report/Kirbylnst _Indigenous_ASR2017-compressed.pdf. Accessed April 26, 2018

26 United States Centers for Disease Control and Prevention. Viral Hepatitis Surveillance, United States, 2015. Atlanta, GA: United States Centers for Disease Control and Prevention; 2017. https:// www.cdc.gov/hepatitis/statistics/2015surveillance/pdfs/2015HepSurveillanceRpt.pdf. Accessed April 26, 2018

27 Parmar P, Corsi DJ, Cooper C. Distribution of hepatitis C risk factors and HCV treatment outcomes among Central Canadian Aboriginal. Can J Gastroenterol Hepatol 2016;2016:8987976
28 Remis RS. Modelling the Incidence and Prevalence of Hepatitis C Infection and its Sequelae in Canada, 2007: Final Report. Public Health Agency of Canada. http://www.phac-aspc.gc.ca/sti-itssurv-epi/model/pdf/model07-eng.pdf. Accessed 11 May 2018

29 Alvarado-Mora MV, Fernandez MFG, Gomes-Gouvêa MS, de Azevedo Neto RS, Carrilho FJ, Pinho JR. Hepatitis B (HBV), hepatitis $\mathrm{C}(\mathrm{HCV})$ and hepatitis delta (HDV) viruses in the Colombian population-how is the epidemiological situation? PLoS One 2011;6(04):e18888

30 Maaroufi A, Vince A, Himatt SM, et al. Historical epidemiology of hepatitis $C$ virus in select countries-volume 4. J Viral Hepat 2017; 24(Suppl 2):8-24

31 Conway J, Tsourtos G, Lawn S. The barriers and facilitators that indigenous health workers experience in their workplace and communities in providing self-management support: a multiple case study. BMC Health Serv Res 2017;17(01):319

32 Marrone S. Understanding barriers to health care: a review of disparities in health care services among indigenous populations. Int J Circumpolar Health 2007;66(03):188-198

33 Gilliver R, Machin W, Kearley J, Lothian R, Chronister K, Read P. Treatment of Aboriginal and Torres Strait Islander Clients with Direct Acting Antivirals at the Kirketon Road Centre: An Integrated Primary Health Care Setting Serving Highly Marginalised Populations. Paper presented at the 11 Australasian Viral Hepatitis Elimination Conference (AVHEC), August 10-11, 2017, Cairns, Queensland, Australia. https://az659834.vo. msecnd.net/eventsairaueprod/production-ashm-public/ 4e0f10ee77634cc2a4a357984cd559d1. Accessed April 26, 2018

34 Reilley B, Leston J, Hariri S, et al. Birth cohort testing for hepatitis C virus - Indian Health Service 2012-2015. MMWR Morb Mortal Wkly Rep 2016;65(18):467-469

35 Mera J, Vellozzi C, Hariri S, et al. Identification and clinical management of persons with chronic hepatitis $C$ virus infection - Cherokee Nation, 2012-2015. MMWR Morb Mortal Wkly Rep 2016;65(18): 461-466

36 Chlibek R, Smetana J, Sosovickova R, et al. Prevalence of hepatitis $C$ virus in adult population in the Czech Republic - time for birth cohort screening. PLoS One 2017;12(04):e0175525

37 Baptista-González H, Noffal-Nuño VM, Méndez-Sánchez N. Frequency of hepatitis $C$ virus infection in a single institution in Mexico with a focus on birth-cohort population. Ann Hepatol 2016;15(06):846-852

38 Bruggmann P, Negro F, Bihl F, et al. Birth cohort distribution and screening for viraemic hepatitis $C$ virus infections in Switzerland. Swiss Med Wkly 2015;145:w14221

39 Rosińska M, Parda N, Kołakowska A, et al. Factors associated with hepatitis $C$ prevalence differ by the stage of liver fibrosis: a crosssectional study in the general population in Poland, 2012-2016. PLoS One 2017;12(09):e0185055

40 Morgan JR, Servidone M, Easterbrook P, Linas BP. Economic evaluation of HCV testing approaches in low and middle income countries. BMC Infect Dis 2017;17(Suppl 1):697

41 Heil J, Hoebe CJPA, Cals JWL, Ter Waarbeek HLG, van Loo IHM, Dukers-Muijrers NHTM. Detecting hepatitis B and C by combined public health and primary care birth cohort testing. Ann Fam Med 2018;16(01):21-27

42 Benova L, Mohamoud YA, Calvert C, Abu-Raddad LJ. Vertical transmission of hepatitis $C$ virus: systematic review and metaanalysis. Clin Infect Dis 2014;59(06):765-773

43 Squires JE, Balistreri WF. Hepatitis $C$ virus infection in children and adolescents. Hepatol Commun 2017;1(02):87-98

44 Lagging M, Wejstål R, Duberg AS, Aleman S, Weiland O, Westin J; for the Swedish Consensus Group. Treatment of hepatitis $C$ virus infection for adults and children: updated Swedish consensus guidelines 2017. Infect Dis (Lond) 2018 ( e-pub ahead of print ). Doi: $10.1080 / 23744235.2018 .1445281$

45 Towers CV, Fortner KB. Infant follow-up postdelivery from a hepatitis C viral load positive mother. J Matern Fetal 
Neonatal Med 2018 ( e-pub ahead of print ). Doi: 10.1080/ 14767058.2018.1458836

46 World Health Organization. Guidelines on Hepatitis B and C Testing. Geneva: World Health Organization; February 2017. http://apps.who.int/iris/bitstream/10665/254621/1/ 9789241549981-eng.pdf?ua=1. Accessed May 10, 2018

47 Urbanus AT, van Keep M, Matser AA, et al. Is adding HCV screening to the antenatal national screening program in Amsterdam, the Netherlands, cost-effective? PLoS One 2013;8(08):e70319

48 Jadoul $M$. The prevention of hepatitis $C$ virus transmission to hemodialysis patients and staff members. Hemodial Int 2018;22 (Suppl 1):S104-S109

49 Ko SY, Choe WH. Management of hepatitis C viral infection in chronic kidney disease patients on hemodialysis in the era of direct-acting antivirals. Clin Mol Hepatol 2018 ( e-pub ahead of print ). Doi: 10.3350/cmh.2017.0063

50 Komitova RT, Atanasova MV, Pavlova TA, Nyagolov MS, Ivanova AV. Diagnostic dilemmas in hepatitis $C$ virus infection for hemodialysis patients. Folia Med (Plovdiv) 2017;59(01):70-77

51 Carvalho-Filho RJ, Feldner AC, Silva AE, Ferraz ML. Management of hepatitis $C$ in patients with chronic kidney disease. World J Gastroenterol 2015;21(02):408-422

52 Goodkin DA, Bieber B, Jadoul M, Martin P, Kanda E, Pisoni RL. Mortality, hospitalization, and quality of life among patients with hepatitis C infection on hemodialysis. Clin J Am Soc Nephrol 2017;12(02):287-297

53 Azmi AN, Tan SS, Mohamed R. Hepatitis C and kidney disease: an overview and approach to management. World J Hepatol 2015;7 (01):78-92

54 Gane E, Lawitz E, Pugatch D, et al. Glecaprevir and pibrentasvir in patients with HCV and severe renal impairment. N Engl J Med 2017;377(15):1448-1455

55 Taneja S, Duseja A, De A, et al. Low-dose sofosbuvir is safe and effective in treating chronic hepatitis $C$ in patients with severe renal impairment or end-stage renal disease. Dig Dis Sci 2018;63 (05):1334-1340

56 Moini M, Ziyaeyan M, Aghaei S, et al. Hepatitis C virus (HCV) infection rate among seronegative hemodialysis patients screened by two methods; HCV core antigen and polymerase chain reaction. Hepat Mon 2013;13(06):e9147

57 Ladino M, Pedraza F, Roth D. Hepatitis C virus infection in chronic kidney disease. J Am Soc Nephrol 2016;27(08):2238-2246

58 Kidney Disease: Improving Global Outcomes (KDIGO) Hepatitis C Work Group. KDIGO 2018 Clinical Practice Guideline on the Prevention, Diagnosis, Evaluation, and Treatment of Hepatitis C in Chronic Kidney Disease. Kidney Int Suppl. In press

59 Jadoul M, Horsmans Y. Towards eradication of hepatitis C virus from dialysis units. Lancet 2015;386(10003):1514-1515

60 Platt L, Easterbrook P, Gower E, et al. Prevalence and burden of $\mathrm{HCV}$ co-infection in people living with HIV: a global systematic review and meta-analysis. Lancet Infect Dis 2016;16(07): 797-808

61 Ingiliz P, Martin TC, Rodger A, et al; NEAT study group. HCV reinfection incidence and spontaneous clearance rates in HIVpositive men who have sex with men in Western Europe. J Hepatol 2017;66(02):282-287

62 Boerekamps A, van den Berk GE, Lauw FN, et al. Declining hepatitis $\mathrm{C}$ virus (HCV) incidence in Dutch human immunodeficiency virus-positive men who have sex with men after unrestricted access to HCV therapy. Clin Infect Dis 2018;66(09): 1360-1365

63 Braun D, Hampel BH, Nguyen H, et al. A Treatment as Prevention Trial to Eliminate HCV in HIV+ MSM: The Swiss HCVree Trial. Paper presented at the Conference on Retroviruses and Opportunistic Infections (CROI), Boston, Massachussetts, March 4-7, 2018 [Abstract no. 81LB]. http://www.croiconference.org/sessions/treatment-prevention-trial-eliminate-hcv-hiv-msm-swiss-hcvree-trial. Accessed April 26, 2018
64 Wyles D, Bräu N, Kottilil S, et al; ASTRAL-5 Investigators. ASTRAL-5 Investigators. Sofosbuvir and velpatasvir for the treatment of hepatitis $C$ virus in patients coinfected with human immunodeficiency virus type 1: an open-label, phase 3 study. Clin Infect Dis 2017;65(01):6-12

65 Bischoff J, Mauss S, Cordes C, et al. Rates of sustained virological response 12 weeks after the scheduled end of direct-acting antiviral (DAA)-based hepatitis C virus (HCV) therapy from the National German HCV registry: does HIV coinfection impair the response to DAA combination therapy? HIV Med 2018;19(04): 299-307

66 Greenaway C, Thu Ma A, Kloda LA, et al. The seroprevalence of hepatitis $C$ antibodies in immigrants and refugees from intermediate and high endemic countries: a systematic review and meta-analysis. PLoS One 2015;10(11):e0141715

67 Feld JJ. Extending a helping hand: addressing hepatitis $\mathrm{C}$ in economic migrants and refugees. Ann Hepatol 2018;17(01): $8-10$

68 Greenaway C, Azoulay L, Allard R, et al. A population-based study of chronic hepatitis $C$ in immigrants and non-immigrants in Quebec, Canada. BMC Infect Dis 2017;17(01):140

69 Sagnelli E, Alessio L, Sagnelli C, et al. Clinical findings of HCV chronic infection in undocumented immigrants and low-income refugees in three areas of southern Italy. Ann Hepatol 2018;17 (01):47-53

70 Prestileo T, Di Lorenzo F, Indovina C, et al; Immigrant Take Care Advocacy (I.Ta.C.A.) team Palermo. Detection of HBV, HCV and HIV infection and linkage to care in migrants: the experience of the I.Ta. C.A. cohort in Palermo. Paper presented at Annual Meeting of the Italian Society of Migration Medicine; April 19, 2018; Catania, Italy

71 Falla AM, Hofstraat SHI, Duffell E, Hahné SJM, Tavoschi L, Veldhuijzen IK. Hepatitis B/C in the countries of the EU/EEA: a systematic review of the prevalence among at-risk groups. BMC Infect Dis 2018;18(01):79

72 Hellard M, Sacks-Davis R, Gold J. Hepatitis C treatment for injection drug users: a review of the available evidence. Clin Infect Dis 2009;49(04):561-573

73 Aspinall EJ, Corson S, Doyle JS, et al. Treatment of hepatitis C virus infection among people who are actively injecting drugs: a systematic review and meta-analysis. Clin Infect Dis 2013;57 (Suppl 2):S80-S89

74 Christensen S, Buggisch P, Mauss S, et al. Direct-acting antiviral treatment of chronic HCV-infected patients on opioid substitution therapy: still a concern in clinical practice? Addiction 2018; 113(05):868-882

75 Ahmad F, Johnston L, Stephens B, et al. Eradicate-C Study: Treating Chaotic Drug Users to Eliminate Hepatitis C - The Final Report. Poster presented at: International Symposium on Hepatitis Care in Substance Users; September 6-8, 2017; Jersey City, New Jersey, United States

76 Gottfreðsson M, Tyrfingsson T, Runarsdottir V, et al. Treatment as Prevention for Hepatitis C (TraP HepC). A Real-world Experience from the First 12 Months of a Nationwide Elimination Program in Iceland. OFID 2017:4(Suppl 1):S42. [Abstract no. 1694]. https:// www.ncbi.nlm.nih.gov/pmc/articles/PMC5632122/pdf/ofx162. 101.pdf. Accessed April 26, 2018

77 Finessi V, Borojevic M, Messina P, et al. Models of Care for the Management of Hepatitis C among People Who Inject Drug in Southern Switzerland: Role of Nurses. Poster presented at: International Symposium on Hepatitis Care in Substance Users; September 6-8, 2017; Jersey City, New Jersey, United States

78 Allardice K, Von Birba S, Doyle JS, et al. Implementation of a Nurse-Led Model of Care to Treat People Who Inject Drugs (PWID) for HCV in the Community. Poster presented at: International Symposium on Hepatitis Care in Substance Users; September 6-8, 2017; Jersey City, New Jersey, United States

79 Read P, Lothian R, Chronister K, et al. Delivering direct acting antiviral therapy for hepatitis $\mathrm{C}$ to highly marginalised and 
current drug injecting populations in a targeted primary health care setting. Int J Drug Policy 2017;47:209-215

80 Olafsson S, Tyrfingsson T, Runarsdottir V, et al. Treatment as Prevention for Hepatitis C (TraP Hep C) - a nationwide elimination programme in Iceland using direct-acting antiviral agents. J Intern Med 2018;283(05):500-507

81 WHO. UNODC, UNAIDS Technical Guide for Countries to Set Targets for Universal Access to HIV Prevention, Treatment and Care for Injecting Drug Users - 2012 Revision. World Health Organization. 2012. Available at: http://apps.who.int/iris/bitstream/handle/10665/77969/9789241504379_eng.pdf;jsessionid=A7DFE2BB27329EB4A29D45B1D544EAA2 ? sequence $=1$. Accessed June 27, 2018

82 Scott N, Ólafsson S, Gottfreðsson M, et al. Modelling the elimination of hepatitis $C$ as a public health threat in Iceland: a goal attainable by 2020. J Hepatol 2018;68(05):932-939

83 Butsashvili M. Hepatitis C Elimination Program in Georgia. Available at: https://www.eiseverywhere.com/file_uploads/6 bec0fda57a3fa45db503d570d21a18d_1515FriMaiaButsashvili. pdf. Accessed April 26, 2018

84 Ministry of Labour, Health and Social Affairs. Strategic Plan for the Elimination of Hepatitis C Virus in Georgia, 2016-2020. Tbilisi, Georgia: Ministry of Labour, Health and Social Affairs; 2016. http://www.moh.gov.ge/uploads/files/2017/akordeoni/ failebi/Georgia_HCV_Elimination_Strategy_2016-2020.pdf. Accessed April 26, 2018

85 ClinicalTrials.gov. Evaluating treatment as prevention among people who inject drugs in Dundee for HCV (ERAPID HCV). Available at: https://clinicaltrials.gov/ct2/show/record/NCT03356405?view =record. Accessed June 27, 2018

86 Papadopoulos N, Argiana V, Deutsch M. Hepatitis C infection in patients with hereditary bleeding disorders: epidemiology, natural history, and management. Ann Gastroenterol 2018;31(01): 35-41

87 Uemura H, Tsukada K, Mizushima D, et al. Interferon-free therapy with direct acting antivirals for HCV/HIV-1 co-infected Japanese patients with inherited bleeding disorders. PLoS One 2017;12(10):e0186255

88 Walsh CE, Workowski K, Terrault NA, et al. Ledipasvir-sofosbuvir and sofosbuvir plus ribavirin in patients with chronic hepatitis $C$ and bleeding disorders. Haemophilia 2017;23(02):198-206

89 Sinakos E, Kountouras D, Koskinas J, et al. Treatment of chronic hepatitis $C$ with direct-acting antivirals in patients with $\beta$ thalassaemia major and advanced liver disease. $\mathrm{Br} \mathrm{J}$ Haematol 2017;178(01):130-136

90 Zachou K, Arvaniti P, Gatselis NK, et al. Patients with haemoglobinopathies and chronic hepatitis C: a real difficult to treat population in 2016? Mediterr J Hematol Infect Dis 2017;9(01): e2017003

91 Department of Health. Press Release. Harris Hails Effective Eradication of Hepatitis C in Haemophilia Patients a Great Achievement for Ireland. December 22, 2016. http://health. gov.ie/blog/press-release/harris-hails-effective-eradication-ofhepatitis-c-in-haemophilia-patients-a-great-achievement-forireland/. Accessed 17 April 2018

92 Matičič M, Lekše A, Kozinc M, et al. Micro-Elimination of Hepatitis C among Patients with Congenital Bleeding Disorders in Slovenia. Slide presentation at the EASL International Liver Congress, April 11-15, 2018, Paris, France [Abstract no. THU 146]. https://ilc-congress.eu/wp-content/uploads/2018/ebooks/ scientific_programme/index.html\#p=192. Accessed April 26, 2018

93 Zampino R, Coppola N, Sagnelli C, Di Caprio G, Sagnelli E. Hepatitis $C$ virus infection and prisoners: epidemiology, outcome and treatment. World J Hepatol 2015;7(21):2323-2330

94 Fridriksdottir RH, Fridriksdottir H, Alexiusdottir K, et al. Outcomes of Treatment for Hepatitis C Virus Infection in the Prison Setting in the TrapHepC (Treatment as Prevention for Hepatitis C) Program in
Iceland. Poster presented at: International Symposium on Hepatitis Care in Substance Users; September 6-8, 2017; Jersey City, New Jersey, United States

95 MacDonald R, Akiyama MJ, Kopolow A, et al. Feasibility of treating hepatitis $C$ in a transient jail population. Open Forum Infect Dis 2017;4(03):ofx142

96 Martin NK, Vickerman P, Brew IF, et al. Is increased hepatitis C virus case-finding combined with current or 8-week to 12-week directacting antiviral therapy cost-effective in UK prisons? A prevention benefit analysis. Hepatology 2016;63(06):1796-1808

97 Bartlett SR, Fox P, Cabatingan H, et al. Demonstration of nearelimination of hepatitis $C$ virus among a prison population: the Lotus Glen Correctional Centre hepatitis C treatment project. Clin Infect Dis 2018 (e -pub ahead of print ). Doi: 10.1093/cid/ ciy210

98 Wright NMJ, Tompkins CNE, Farragher TM. Injecting drug use in prison: prevalence and implications for needle exchange policy. Int J Prison Health 2015;11(01):17-29

99 Lafferty L, Rance J, Treloar C. Who goes first? Understanding hepatitis $\mathrm{C}$ risk among injecting networks in the prison setting. Drug Alcohol Depend 2018;183:96-101

100 Lloyd AR, Clegg J, Lange J, et al. Safety and effectiveness of a nurse-led outreach program for assessment and treatment of chronic hepatitis C in the custodial setting. Clin Infect Dis 2013; 56(08):1078-1084

101 Papaluca T, McDonald L, Craigie A, et al. Outcomes of a nurse-led model of care for HCV treatment in Victorian prisons. Slide presentation at the Australasian Viral Hepatitis Elimination Conference (AVHEC), August 10-11, 2017, Cairns, Queensland, Australia. https://az659834.vo.msecnd.net/eventsairaueprod/ production-ashm-public/c56e6906b81344febe63b9f5f53a6743. Accessed April 26, 2018

102 Crespo J. A Program of Testing and Treat Intended to Eliminate Hepatitis C in a Prison: The JAILFREE-C Study. AASLD Liver Learning. Nov 12, 2016; 143810. http://liverlearning.aasld.org/ aasld/2016/thelivermeeting/143810/javier.crespo.a.program.of. testing.and.treat.intended.to.eliminate.hepatitis.c.html. Accessed April 26, 2018

103 Cuadrado A, Llerena S, Cobo C, et al. Microenvironment eradication of hepatitis C: a novel treatment paradigm. Am J Gastroenterol 2018. Doi: 10.1038/s41395-018-0157-x. [Epub ahead of print]

104 Beckwith CG, Kurth AE, Bazerman LB, et al. A pilot study of rapid hepatitis $C$ virus testing in the Rhode Island Department of Corrections. J Public Health (Oxf) 2016;38(01):130-137

105 Samur S, Kues B, Ayer T, et al. Cost effectiveness of pre- vs postliver transplant Hepatitis $C$ treatment with direct-acting antivirals. Clin Gastroenterol Hepatol 2018;16(01):115-122.e10

106 Liapakis A, Formica RN, Levitsky J. Solid organ transplantation of viral hepatitis $C$ positive donor organs into viral hepatitis $C$ negative recipients. Curr Opin Organ Transplant 2018;23(02):257-263

107 Holscher CM, Durand CM, Desai NM. Expanding the use of organs from hepatitis C-viremic donors: the evidence continues to build. Transplantation 2018;102(04):546-547

108 World Health Organization. Monitoring and Evaluation for Viral Hepatitis B and C: Recommended Indicators and Framework. Geneva:World Health Organization; 2016. http://apps. who.int/iris/bitstream/10665/204790/1/9789241510288_eng. pdf?ua $=1$. Accessed May 10, 2018

109 EASL. Hepatitis C Virus Elimination Programmes Report Encouraging Results: Is Elimination Within Reach? [Public release]. https://ilc-congress.eu/wp-content/uploads/2018/04/ ILC-2018-Press-Kit_FRI_SATv3.pdf. Accessed April 23, 2018

110 El-Shabrawi MH, Kamal NM. Burden of pediatric hepatitis C. World J Gastroenterol 2013;19(44):7880-7888

111 Indolfi G, Hierro L, Dezsofi A, et al. Treatment of chronic hepatitis $C$ virus infection in children: a position paper by the Hepatology Committee of European Society of Paediatric Gastroenterology, 
192 Micro-Elimination Approach to Eliminating Hepatitis C Lazarus et al.

Hepatology and Nutrition. J Pediatr Gastroenterol Nutr 2018;66 (03):505-515

112 Lindsay A. Report of the Tribunal of Inquiry into the Infection with HIV and Hepatitis C of Persons with Haemophilia and Related Matters. Dublin: The Stationery Office, Government of Ireland; 2002. http://health.gov.ie/wp-content/uploads/2014/ 04/Tribunal-o-Inquiry-into-the-Infection-with-HIV-and-HepC-of-persons-with-Haemophilia-and-Related-Matters.pdf. Accessed April 26, 2018
113 Irish Haemophilia Society. Press Release. Irish Haemophilia Society Announces the Effective Eradication of Hepatitis C in People with Haemophilia in Ireland. December 22, 2016. https:// haemophilia.ie/wp-content/uploads/2016/02/22-12-16-Eradication-of-Hep-C-Press-Release.pdf. Accessed 11 May 2018

114 National Hepatitis C Treatment Programme. Ireland's Health Service. https://www.hse.ie/eng/about/who/primarycare/hepcprogramme.html. Accessed April 24, 2018 